\title{
Breast cancer chemopreventive and chemotherapeutic effects of Camellia Sinensis (green tea): an updated review
}

\author{
Mahmoud Rafieian-Kopaei ${ }^{1}$, Mino Movahedi ${ }^{2}$
}

${ }^{1}$ Full Professor, Medical Plants Research Center, Shahrekord University of Medical Sciences, Shahrekord, Iran

${ }^{2}$ Mino Movahedi, MD in Obstetrics and Gynecology, Assistant Professor, School of Medicine, Isfahan University of Medical Sciences, Isfahan, Iran

Type of article: Review

\begin{abstract}
Introduction: Camellia sinensis belongs to the plant family of Theaceae, native to East Asia, the Indian Subcontinent and Southeast Asia, but naturalized in many parts of the world. The aim of this study was to overview its anti-breast cancer chemopreventive and chemotherapeutic effects. This review article is aimed to overview breast cancer chemopreventive and chemotherapeutic effects of Camellia sinensis (green tea).

Methods: This review article was carried out by searching studies in PubMed, Medline, Web of Science, and IranMedex databases. The initial search strategy identified around 108 references. In this study, 68 studies were accepted for further screening, and met all our inclusion criteria [in English, full text, chemopreventive and chemotherapeutic effects of Camellia sinensis and dated mainly from the year 1999 to 2016. The search terms were Camellia sinensis, chemopreventive, chemotherapeutic properties, pharmacological effects.

Result: The result of this study suggested that the catechin available in Camellia sinensis has properties which can prevent and treat breast cancer. It has also been shown to inhibit proliferation of breast cancer cells and to block carcinogenesis. It was found that increased Camellia sinensis consumption may lower the risk of breast cancer. Camellia sinensis intake was shown to reduce the risk of breast cancer incidence. In addition, potential breast cancer chemopreventive effect of Camellia sinensis both in vivo and in vitro was highly confirmed. However, the evidence of low effect and no effect was observed. More clinical trial studies are needed to prove its anti-breast cancer activity decisively.

Conclusion: Camellia sinensis is broadly utilized as a part of customary medication since antiquated time because of its cost adequacy, and fewer reaction properties. The studies demonstrated anti-breast cancer activity of Camellia sinensis and its component by adjusting cell signaling pathways such as angiogenesis, apoptosis, and transcription factor. Furthermore, Camellia sinensis and its chemical compound was shown to be extremely useful in the development of novel anticancer medications.
\end{abstract}

Keywords: Camellia sinensis, chemopreventive, chemotherapeutic, catechins, Phytochemicals

\section{Introduction}

\section{Background}

The therapeutic role of herbal medicine in the treatment of various diseases, were investigated and confirmed (1-13). Camellia sinensis belongs to family Theaceae, is indigenous to East Asia and cultivated worldwide in tropical and subtropical areas. It is a species of hardy shrub, whose leaves and leaf buds are used to make tea. The seeds of Camellia sinensis are used for therapeutic and cosmetic purposes, and emanate from the leaves of another herb. Camellia sinensis (green tea) is a Chinese tea, popularly consumed as a healthy beverage, and has been demonstrated to possess various therapeutic activities, including antioxidants (14-17), anti obesity (18) and anticancer $(19,20)$, wound healing (21), cognitive and memory improvement (22), anti-inflammatory (23), anti arthritic (24), antibacterial (25), antimicrobial (26, 27), antiangiogenic (28), antiviral (29), cholesterol-lowering

\section{Corresponding author:}

Assistant Professor Dr. Mino Movahedi, School of Medicine, Isfahan University of Medical Sciences, Isfahan, Iran. Tel: +989131192140, Fax: +983332246, Email: saeidi@med.mui.ac.ir

Received: November 01, 2016, Accepted: January 18, 2017, Published: February 2017

iThenticate screening: December 15, 2016, English editing: January 28, 2017, Quality control: February 01, 2017

(C) 2017 The Authors. This is an open access article under the terms of the Creative Commons Attribution-NonCommercialNoDerivs License, which permits use and distribution in any medium, provided the original work is properly cited, the use is non-commercial and no modifications or adaptations are made. 
effects (30) and anti-kidney injury (4). The leaves contribute to cure asthma, angina pectoris, vascular disease, and diabetes $(3,31)$. It has been found to possess neuroprotective effect $(32)$. It can also contribute to the treatment of cardiovascular diseases (33). Camellia sinensis possesses healing effects due to its polyphenol content $(34,35)$, especially flavonols. The main constituent of herb is Catechins, which are a sort of polyphenol, and have a modulatory effect in the various genes in the development and progression of cancer. The major Catechins consist of: epicatechin (EC), -epicatechin-3-gallate (ECG), epigallocatechin (EGC), and epigallocatechin-3-gallate (EGCG) $(36,37)$. EGCG is one of the most abundant Catechins containing about $50-80 \%$ of the total content of Catechins (38).

\subsection{Statement of problem}

There are many medicinal herbs containing natural compositions that have properties which can treat and cure many diseases. The diversity of natural compounds in herbs and their various roles in preventing and treating different diseases together with the naturalness and compatibility with the body, and having no adverse effects, motivate people to have more interest in their application, and researchers to have much more inclination towards studies on them and recognize their curative effects. However, there is still elusion regarding their efficacy, pharmacological dosage and toxicity. To achieve this purpose, lots of studies have been carried out to concentrate on the ability of herbs to generate a favorable chemical and pharmacological profile. Breast cancer is a dangerous and fatal disease. To cure such a cancer, the intake of a natural agent with no side effects, is of high importance.

\subsection{Objective of research}

This review article is aimed to overview breast cancer chemopreventive and chemotherapeutic effects of Camellia sinensis (green tea).

\section{Material and Methods}

This review was carried out by searching studies in PubMed, Medline, Web of Science, and IranMedex databases. The initial search strategy identified around 108 references. In this study, 68 studies were accepted for further screening and met all our inclusion criteria [in English, full text, chemopreventive and chemotherapeutic effects of Camellia sinensis]. Inclusion criteria were the following key words used to search for the relevant articles published from 1999 to 2016, their full text should be available in English. Articles included consisted of clinical trials, in vitro, in vivo, review, or meta-analysis studies. Exclusion criteria were when only abstract was available, not in the timeline of study. Those articles not matching our inclusion criteria (in other languages than English, between the timeline of study) were excluded from the study.

\section{Results}

Increased Camellia sinensis consumption may be inversely associated with risk of breast cancer recurrence. Furthermore, it showed that this plant is a promising breast cancer chemopreventive candidate via mechanistic actions of tea polyphenols in growth factor signaling, angiogenesis and lipid metabolism (39). Treatment of 4T1 cells with Camellia sinensis aqueous extract, resulted in significant inhibition of 4T1 cell proliferation via 4T1 apoptosis in a dose-dependent manner. This extract was shown to contribute in bone protection against breast cancer-induced bone destruction (40). In another study, it was recommended that further clinical trial study with large sample size on the efficacy of Camellia sinensis polyphenols or extracts are required, before a definitive decision can be made for its cancer prevention (41). The individual and combined effects of PCB 102 and EGCG on cell proliferation was evaluated. It was shown that Camellia sinensis which possesses potential chemoprevention of breast cancer through the process of EGCG, suppressed the proliferation-stimulating activity of the environmental estrogen PCB 102. Tea or Camellia sinensis drinking was not found to be associated with overall breast cancer risk. As the result was drawn on pre- and post-menopausal women, it may be interfered (42). In a clinical trial study, the role of daily Camellia sinensis intake was investigated for 12 months on biomarkers of breast cancer risk. The result showed a potential anti-breast cancer for green tea (43). In a clinical trial study, GTE on breast cancer biomarkers was investigated. The result showed that daily intake of GTE is generally well tolerated by a group of mainly postmenopausal women (44). In a human study of the role of coffee and tea consumption, caffeine intake was assessed. Findings suggested that coffee and caffeine intake lower the risk of breast cancer, while tea consumption increased the risk of breast cancer (45). Higher caffeinated coffee intake has lower risk of postmenopausal breast cancer, while decaffeinated coffee intake does not have any effect on breast cancer (46). Estrogen receptordependent and independent mechanisms are responsible to the treatment of estrogen receptor-positive and estrogen receptor-negative breast cancer. There was no interaction of herb Catechins with aromatase inhibitors or fulvestrant (47). Combination of Arc and EGCG with Cur in both cell lines, showed the strongest effects on cell cycle arrest 
and apoptosis increasing chemoprevention in both prostate and breast cancer (48). Camellia sinensis polyphenols and their applications in the prevention and treatment of breast cancer was investigated. The result showed a potential effect of Camellia sinensis components on breast cancer (49). Effect of Camellia sinensis in women with primary breast cancer was assessed. The result showed a decrease in Ki-67 in both benign and malignant cells in the Camellia sinensis group, confirming its anti- breast cancer activity (50). The relationship between Camellia sinensis utilization and breast cancer in light of the hormone receptor status of tumors was inspected. No considerable impact adjustment was seen for menopausal status, 4 SNPs, or dietary consumption of folate or isoflavone. This research showed that Camellia sinensis intake does not decrease the venture of breast cancer (51). In a Japanese population, it was found that there was no association between Camellia sinensis intake and risk of breast cancer (52). The beneficial effect of Camellia sinensis in breast cancer therapy is because of the modification of the breast cancer miRNA expression profile, as well as the altered miRNA regulation of potential oncogenes and tumor-suppressor genes (53). In a hormone-resistant breast cancer approach study, the anti-breast cancer effect of Camellia sinensis extract was attributed to ER $\alpha$ expression restoring by epigenetic mechanisms regulation and HDAC inhibitor combination (54). The impact of every day utilization of decaffeinated Camellia sinensis for 6 months on weight and body arrangement, metabolic parameters and lipid profiles in overweight breast growth survivors, was tried. Consumption of decaffeinated Camellia sinensis for 6 months resulted in reduced weight and improvement in HDL and glucose homeostasis (55). Suppression of catechol-Omicron-methyltransferases action in human breast carcinoma cells could expand the proteasome-inhibitory intensity of EGCG and in this way, upgrade its tumor cell development inhibitory action. COMT inhibition probably expands anti-cancer activity of tea polyphenols, and the mix may be utilized as a new method or supplementary therapy for breast carcinoma chemotherapy (56).

The effects of EGCG on the migration and invasion of MCF-7 cells was examined. The result illustrated that the inhibitory effect of EGCG on MCF-7 cell migration and invasion may be caused by a down regulation of VASP expression through the Racl pathway in a concentration-dependent manner (57). Among premenopausal women, reduced risk was observed for years of Camellia sinensis drinking $(\mathrm{P}$-trend $=0.02)$, and a dose-response relationship with the amount of tea consumed per month was also observed $(\mathrm{P}$-trend $=0.046)$. Thus, the result demonstrated that Camellia sinensis intake may be loosely associated with a decreased risk of breast cancer (58). In a Chinese population, higher dietary intake of combination of mushrooms and Camellia sinensis reduced breast cancer risk in pre- and postmenopausal women (59). There was a protective effect against breast cancer and Camellia sinensis intake was investigated. The result showed no relationship between Camellia eating and breast cancer venture. Furthermore, results propose that folate pathway restraint might be one mechanism via which Camellia sinensis secures against breast cancer (60). The impact of Camellia sinensis Catechins on breast cell carcinogenesis has been explored. Camellia sinensis Catechins was reported to act in high concentrations or by endocrine treatment (61). Inhibitory impact of EGCG on stifling tumor angiogenesis and breast cancer advancement was explored. The findings support the idea that EGCG specifically targets both tumor cells and tumor vasculature, consequently restraining tumor development, expansion, relocation, and angiogenesis of breast disease (62). The GTC activity at non-cytotoxic levels was investigated. It was identified that GTC was successful in stifling NNK-and B[a] Pinstigated cell carcinogenesis. GTC might be utilized as a part of dietary and chemoprevention of breast cell carcinogenesis connected with long haul presentation to low measurements of natural cancer-causing agents (63).

\section{Discussion}

It is of high importance to identify a healthy lifestyle which will reduce the risk of breast cancer. Although there has been much progress in its treatment, there is still high a rate of mortality from breast cancer. Medical care methodologies are needed for chemoprevention of high risk women and for the treatment of receptor negative breast tumors. In this study, the chemopreventive and chemotherapeutic breast cancer potential of Camellia sinensis was reviewed. In addition, the mechanisms of action of Camellia sinensis intake against breast cancer was discussed. Furthermore, the phytochemical property of plant against breast carcinogenesis was overviewed. Several studies have demonstrated strong chemopreventive and chemotherapeutic actions of Camellia sinensis polyphenols against cancer. This chemopreventive effect was attributed from one side, to its chemical compound (38) and on the other side, to its mechanistic action $(39,54,60,64,65)$. The plant enjoys an anticancer agent partly by regulating epigenetic processes in ER $\alpha$ silencing in breast cancer lines (54). There are several anti-breast cancer mechanisms of action of Camellia sinensis. Inhibiting the Folate pathway is the mechanism of cancer preventive activities of EGCG (60). Another mechanism of action of Camellia sinensis is to inhibit the neoplastic process (62). Green tea extraction appeared to be compelling in smothering NNK-and B[a] P-incited cell carcinogenesis. GTC might be utilized as a part of nourishment and chemoprevention of breast cell carcinogenesis (63). All these mechanisms contribute to prevent and inhibit the cancer processes (initiation, promotion and progress) through the herb uptake. However, 
clinical studies show contradictory results. Many factors possess a serious effect on the ultimate effect of plant polyphenols on the carcinogenesis process, including the beverage temperature, the period of consumption, and the amount of consumed tea in proportion to diet (66). Polyphenol, epigallocatechin-3-gallate (EGCG) is the main chemical compound and an anticancer agent accessible in Camellia sinensis (36). Catechins present in the plant, hold chemoprevention breast cancer activity via inhibitory impacts of epigallocatechin gallate on the development of existing tumors consisting breast disease (67). Camellia sinensis polyphenol epigallocatechin gallate (EGCG) and curcumin (Cur) increases the chemopreventive ability of individual compounds.

\section{Conclusions}

Camellia sinensis has been widely used in traditional medicine since ancient times due to its cost efficacy, and fewer side effect properties. The studies demonstrated anti-breast cancer activity of Camellia sinensis and its constituents, by modulating cell signaling pathways including angiogenesis, apoptosis, and transcription factor. Furthermore, Camellia sinensis and its chemical compound were shown to be very helpful in the construction of novel anticancer drugs.

\section{Acknowledgments:}

The author of this manuscript gives thanks to the Research and Technology Deputy of Shahrekord University of Medical Sciences for their technical and financial support. Moreover, we appreciate all those whom cooperated in this research.

\section{Conflict of Interest:}

There is no conflict of interest to be declared.

\section{Authors' contributions:}

Both authors contributed to this project and article equally. Both authors read and approved the final manuscript.

\section{References:}

1) Nasri H, Hajian S, Ahmadi A, Baradaran A, Kohi G, Nasri P, et al. Ameliorative effect of green tea against contrast-induced renal tubular cell injury. Iran J Kidney Dis. 2015; 9(6): 421-6. PMID: 26552347.

2) Bahmani M, Sarrafchi A, Shirzad H, Rafieian-Kopaei M. Autism: Pathophysiology and Promising Herbal Remedies. Current pharmaceutical design. 2016; 22(3): 277-85. doi: 10.2174/1381612822666151112151529. PMID: 26561063.

3) Nasri H, Rafieian-Kopaei M. Comment on: The effects of green tea consumption on metabolic and anthropometric indices in patients with type 2 diabetes. J Res Med Sci. 2014; 19(12): 1203-4. PMID: 25709665, PMCID: PMC4333532.

4) Nasri H, Ahmadi A, Baradaran A, Nasri P, Hajian S, Pour-Arian A, et al. A biochemical study on ameliorative effect of green tea (Camellia sinensis) extract against contrast media induced acute kidney injury. Journal of renal injury prevention. 2014; 3(2): 47-9. doi: 10.12861/jrip.2014.16. PMID: 25340167, PMCID: PMC4206045.

5) Rafieian-Kopaei M, Saki K, Bahmani M, Ghafourian S, Sadeghifard N, Taherikalani M. Listeriosis Phytotherapy: A Review Study on the Effectiveness of Iranian Medicinal Plants in Treatment of Listeriosis. J Evid Based Complementary Altern Med. 2015. doi: 10.1177/2156587215621460.

6) Shaygannia E, Bahmani M, Zamanzad B, Rafieian-Kopaei M. A Review Study on Punica granatum L. J Evid Based Complementary Altern Med. 2016; 21(3): 221-7. doi: 10.1177/2156587215598039. PMID: 26232244.

7) Miraj S, Rafieian K, Kiani S. Melissa officinalis L: A Review Study With an Antioxidant Prospective. Journal of evidence-based complementary \& alternative medicine. 2016. doi: 10.1177/2156587216663433.

8) Baharvand-Ahmadi B, Bahmani M, Tajeddini P, Rafieian-Kopaei M, Naghdi N. An ethnobotanical study of medicinal plants administered for the treatment of hypertension. J Renal Inj Prev. 2016; 5(3): 123-8. doi: 10.15171/jrip.2016.26. PMID: 27689107, PMCID: PMC5039997.

9) Mesripour A, Rafieian-Kopaei M, Bahrami B. The effects of Anethum graveolens essence on scopolamineinduced memory impairment in mice. Res Pharm Sci. 2016; 11(2): 145-51. PMID: 27168754, PMCID: PMC4852659.

10) Asgharzade S, Rafieian-Kopaei M, Mirzaeian A, Reiisi S, Salimzadeh L. Aloe vera toxic effects: expression of inducible nitric oxide synthase (iNOS) in testis of Wistar rat. Iran J Basic Med Sci. 2015; 18(10): 967-73. PMID: 26730330, PMCID: PMC4686580. 
11) Sarrafchi A, Bahmani M, Shirzad H, Rafieian-Kopaei M. Oxidative stress and Parkinson's disease: New hopes in treatment with herbal antioxidants. Current pharmaceutical design. 2016; 22(2): 238-46. doi: $10.2174 / 1381612822666151112151653$.

12) Rouhi-Boroujeni H, Rouhi-Boroujeni H, Gharipour M, Mohammadizadeh F, Ahmadi S, Rafieian-Kopaei M. Systematic review on safety and drug interaction of herbal therapy in hyperlipidemia: a guide for internist. Acta Biomed. 2015; 86(2): 130-6. PMID: 26422426.

13) Nasri H, Ardalan MR, Rafieian-Kopaei M. Mechanistic Impacts of Medicinal Plants in Diabetic Kidney Disease. Iran J Public Health. 2014; 43(9): 1311-3. PMID: 26175992, PMCID: PMC4500440.

14) Forester SC, Lambert JD. The role of antioxidant versus pro-oxidant effects of green tea polyphenols in cancer prevention. Mol Nutr Food Res. 2011; 55(6): 844-54. doi: 10.1002/mnfr.201000641. PMID: 21538850 , PMCID: PMC3679539.

15) Basu A, Betts NM, Mulugeta A, Tong C, Newman E, Lyons TJ. Green tea supplementation increases glutathione and plasma antioxidant capacity in adults with the metabolic syndrome. Nutr Res. 2013; 33(3): 180-7. doi: 10.1016/j.nutres.2012.12.010. PMID: 23507223, PMCID: PMC3603270.

16) Lambert JD, Elias RJ. The antioxidant and pro-oxidant activities of green tea polyphenols: a role in cancer prevention. Arch Biochem Biophys. 2010; 501(1): 65-72. doi: 10.1016/j.abb.2010.06.013. PMID: 20558130, PMCID: PMC2946098.

17) Parsaei P, Karimi M, Asadi SY, Rafieian-Kopaei M. Bioactive components and preventive effect of green tea (Camellia sinensis) extract on post-laparotomy intra-abdominal adhesion in rats. Int J Surg. 2013; 11(9): 811-5. doi: 10.1016/j.ijsu.2013.08.014. PMID: 23994005.

18) Sae-tan S, Grove KA, Lambert JD. Weight control and prevention of metabolic syndrome by green tea. Pharmacol Res. 2011; 64(2): 146-54. doi: 10.1016/j.phrs.2010.12.013. PMID: 21193040, PMCID: PMC3123415.

19) Hou IC, Amarnani S, Chong MT, Bishayee A. Green tea and the risk of gastric cancer: Epidemiological evidence. World J Gastroenterol. 2013; 19(24): 3713-22. doi: 10.3748/wjg.v19.i24.3713. PMID: 23840110, PMCID: PMC3699047.

20) Davalli P, Rizzi F, Caporali A, Pellacani D, Davoli S, Bettuzzi S, et al. Anticancer Activity of Green Tea Polyphenols in Prostate Gland. Oxid Med Cell Longev. 2012; 2012: 984219. doi: 10.1155/2012/984219. PMID: 22666523, PMCID: PMC3362217.

21) Asadi SY, Parsaei P, Karimi M, Ezzati S, Zamiri A, Mohammadizadeh F, et al. Effect of green tea (Camellia sinensis) extract on healing process of surgical wounds in rat. Int J Surg. 2013; 11(4): 332-7. doi: 10.1016/j.ijsu.2013.02.014. PMID: 23459184.

22) Noguchi-Shinohara M, Yuki S, Dohmoto C, Ikeda Y, Samuraki M, Iwasa K, et al. Consumption of green tea, but not black tea or coffee, is associated with reduced risk of cognitive decline. PLoS ONE. 2014; 9(5): e96013. doi: 10.1371/journal.pone.0096013. PMID: 24828424, PMCID: PMC4020750.

23) Tipoe GL, Leung TM, Hung MW, Fung ML. Green tea polyphenols as an anti-oxidant and antiinflammatory agent for cardiovascular protection. Cardiovasc Hematol Disord Drug Targets. 2007; 7(2): 135-44. doi: 10.2174/187152907780830905. PMID: 17584048.

24) Haqqi TM, Anthony DD, Gupta S, Ahmad N, Lee MS, Kumar GK, et al. Prevention of collagen-induced arthritis in mice by a polyphenolic fraction from green tea. Proc Natl Acad Sci U S A. 1999; 96(8): 4524-9. doi: 10.1073/pnas.96.8.4524. PMID: 10200295, PMCID: PMC16365.

25) Lin SP, Li CY, Suzuki K, Chang CK, Chou KM, Fang SH. Green Tea Consumption after Intense Taekwondo Training Enhances Salivary Defense Factors and Antibacterial Capacity. PLoS ONE. 2014; 9(1): e87580. doi: 10.1371/journal.pone.0087580. PMID: 24498143, PMCID: PMC3907556.

26) Stoicov C, Saffari R, Houghton J. Green tea inhibits Helicobacter growth in vivo and in vitro. Int J Antimicrob Agents. 2009; 33(5): 473-8. doi: 10.1016/j.ijantimicag.2008.10.032. PMID: 19157800, PMCID: PMC2694061.

27) Reygaert WC. The antimicrobial possibilities of green tea. Front Microbiol. 2014; 5: 434. doi: 10.3389/fmicb.2014.00434. PMID: 25191312, PMCID: PMC4138486.

28) Sartippour M, Shao Z, Heber D. Green tea inhibits vascular endothelial growth factor (VEGF) induction in human breast cancer cells.(Abstracts). Alternative Medicine Review. 2002; 7(5): 429-30.

29) Weber JM, Ruzindana-Umunyana A, Imbeault L, Sircar S. Inhibition of adenovirus infection and adenain by green tea catechins. Antiviral Res. 2003; 58(2): 167-73. doi: 10.1016/S0166-3542(02)00212-7. PMID: 12742577 . 
30) Maron DJ, Lu GP, Cai NS, Wu ZG, Li YH, Chen H, et al. Cholesterol-lowering effect of a theaflavinenriched green tea extract: a randomized controlled trial. Arch Intern Med. 2003; 163(12): 1448-53. doi: 10.1001/archinte.163.12.1448. PMID: 12824094.

31) Toolsee NA, Aruoma OI, Gunness TK, Kowlessur S, Dambala V, Murad F, et al. Effectiveness of Green Tea in a Randomized Human Cohort: Relevance to Diabetes and Its Complications. Biomed Res Int. 2013; 2013: 412379. doi: 10.1155/2013/412379. PMID: 24102055, PMCID: PMC3786468.

32) Liu JB, Zhou L, Wang YZ, Wang X, Zhou Y, Ho WZ, et al. Neuroprotective Activity of (-)Epigallocatechin Gallate against Lipopolysaccharide-Mediated Cytotoxicity. J Immunol Res. 2016; 2016 : 4962351. doi: 10.1155/2016/4962351. PMID: 27191001, PMCID: PMC4844887.

33) Sueoka N, Suganuma M, Sueoka E, Okabe S, Matsuyama S, Imai K, et al. A new function of green tea: prevention of lifestyle-related diseases. Ann N Y Acad Sci. 2001; 928(1): 274-80. doi: 10.1111/j.17496632.2001.tb05656.x. PMID: 11795518.

34) Kanwar J, Taskeen M, Mohammad I, Huo C, Chan TH, Dou QP. Recent advances on tea polyphenols. Front Biosci (Elite Ed). 2012; 4: 111-31. doi: 10.2741/e363. PMID: 22201858, PMCID: PMC3303150.

35) Johnson JJ, Bailey HH, Mukhtar H. Green tea polyphenols for prostate cancer chemoprevention: a translational perspective. Phytomedicine. 2010; 17(1): 3-13. doi: 10.1016/j.phymed.2009.09.011. PMID: 19959000, PMCID: PMC2789276.

36) Balentine DA, Wiseman SA, Bouwens LC. The chemistry of tea flavonoids. Crit Rev Food Sci Nutr. 1997; 37(8): 693-704. doi: 10.1080/10408399709527797. PMID: 9447270.

37) Higdon JV, Frei B. Tea catechins and polyphenols: health effects, metabolism, and antioxidant functions. Crit Rev Food Sci Nutr. 2003; 43(1): 89-143. doi: 10.1080/10408690390826464. PMID: 12587987.

38) Mukhtar H, Ahmad N. Tea polyphenols: prevention of cancer and optimizing health. The American journal of clinical nutrition. 2000; 71(6 Suppl): 1698S-702S; discussion 703S-4S. PMID: 10837321.

39) Crew KD, Ho KA, Brown P, Greenlee H, Bevers TB, Arun B, et al. Effects of a green tea extract, Polyphenon E, on systemic biomarkers of growth factor signalling in women with hormone receptor negative breast cancer. J Hum Nutr Diet. 2015; 28(3): 272-82. doi: 10.1111/jhn.12229. PMID: 24646362, PMCID: PMC4205214.

40) Luo KW, Ko CH, Yue GG, Lee JK, Li KK, Lee M, et al. Green tea (Camellia sinensis) extract inhibits both the metastasis and osteolytic components of mammary cancer 4T1 lesions in mice. J Nutr Biochem. 2014; 25(4): 395-403. doi: 10.1016/j.jnutbio.2013.11.013. PMID: 24561153.

41) Yuan JM. Cancer prevention by green tea: evidence from epidemiologic studies. Am J Clin Nutr. 2013; 98(6 Suppl): 1676S-81S. doi: 10.3945/ajcn.113.058271. PMID: 24172305, PMCID: PMC3831544.

42) Li M, Tse LA, Chan WC, Kwok CH, Leung SL, Wu C, et al. Evaluation of breast cancer risk associated with tea consumption by menopausal and estrogen receptor status among Chinese women in Hong Kong. Cancer Epidemiol. 2016; 40: 73-8. doi: 10.1016/j.canep.2015.11.013. PMID: 26680603.

43) Samavat H, Dostal AM, Wang R, Bedell S, Emory TH, Ursin G, et al. The Minnesota Green Tea Trial (MGTT), a randomized controlled trial of the efficacy of green tea extract on biomarkers of breast cancer risk: study rationale, design, methods, and participant characteristics. Cancer Causes Control. 2015; 26(10): 1405-19. doi: 10.1007/s10552-015-0632-2. PMID: 26206423, PMCID: PMC4567901.

44) Dostal AM, Samavat H, Bedell S, Torkelson C, Wang R, Swenson K, et al. The safety of green tea extract supplementation in postmenopausal women at risk for breast cancer: results of the Minnesota Green Tea Trial. Food Chem Toxicol. 2015; 83: 26-35. doi: 10.1016/j.fct.2015.05.019. PMID: 26051348, PMCID: PMC4540665.

45) Seely D, Mills EJ, Wu P, Verma S, Guyatt GH. The effects of green tea consumption on incidence of breast cancer and recurrence of breast cancer: a systematic review and meta-analysis. Integr Cancer Ther. 2005; 4(2): 144-55. doi: 10.1177/1534735405276420. PMID: 15911927.

46) Oh JK, Sandin S, Ström P, Löf M, Adami HO, Weiderpass E. Prospective study of breast cancer in relation to coffee, tea and caffeine in Sweden. Int J Cancer. 2015; 137(8): 1979-89. doi: 10.1002/ijc.29569. PMID: 25885188.

47) Tyagi $\mathrm{T}$, Treas JN, Mahalingaiah PK, Singh KP. Potentiation of growth inhibition and epigenetic modulation by combination of green tea polyphenol and 5-aza-2' -deoxycytidine in human breast cancer cells. Breast Cancer Res Treat. 2015; 149(3): 655-68. doi: 10.1007/s10549-015-3295-5. PMID: 25663548.

48) Bhoo-Pathy N, Peeters PH, Uiterwaal CS, Bueno-de-Mesquita HB, Bulgiba AM, Bech BH, et al. Coffee and tea consumption and risk of pre-and postmenopausal breast cancer in the European Prospective Investigation into Cancer and Nutrition (EPIC) cohort study. Breast Cancer Res. 2015; 17: 15. doi: 10.1186/s13058-015-0521-3. PMID: 25637171, PMCID: PMC4349221. 
49) Yiannakopoulou EC. Interaction of Green Tea Catechins with Breast Cancer Endocrine Treatment: A Systematic Review. Pharmacology. 2014; 94(5-6): 245-8. doi: 10.1159/000369170. PMID: 25471334.

50) Wang P, Wang B, Chung S, Wu Y, Henning SM, Vadgama JV. Increased chemopreventive effect by combining arctigenin, green tea polyphenol and curcumin in prostate and breast cancer cells. RSC Adv. 2014; 4(66): 35242-50. doi: 10.1039/C4RA06616B. PMID: 25243063, PMCID: PMC4166488.

51) Li MJ, Yin YC, Wang J, Jiang YF. Green tea compounds in breast cancer prevention and treatment. World J Clin Oncol. 2014; 5(3): 520-8. doi: 10.5306/wjco.v5.i3.520. PMID: 25114865, PMCID: PMC4127621.

52) Yu SS, Spicer DV, Hawes D, Tseng CC, Yang CS, Pike MC, et al. Biological effects of green tea capsule supplementation in pre-surgery postmenopausal breast cancer patients. Front Oncol. 2013; 3: 298. doi: 10.3389/fonc.2013.00298. PMID: 24380073, PMCID: PMC3861892.

53) Iwasaki M, Mizusawa J, Kasuga Y, Yokoyama S, Onuma H, Nishimura H, et al. Green tea consumption and breast cancer risk in Japanese women: a case-control study. Nutr Cancer. 2014; 66(1): 57-67. doi: 10.1080/01635581.2014.847963. PMID: 24274352.

54) Iwasaki M, Inoue M, Sasazuki S, Sawada N, Yamaji T, Shimazu T, et al. Green tea drinking and subsequent risk of breast cancer in a population to based cohort of Japanese women. Breast Cancer Res. 2010; 12(5): R88. doi: 10.1186/bcr2756. PMID: 22889409, PMCID: PMC3096981.

55) Fix LN, Shah M, Efferth T, Farwell MA, Zhang B. MicroRNA expression profile of MCF-7 human breast cancer cells and the effect of green tea polyphenon-60. Cancer Genomics Proteomics. 2010; 7(5): 261-77. PMID: 20952761.

56) Li Y, Yuan YY, Meeran SM, Tollefsbol TO. Synergistic epigenetic reactivation of estrogen receptor- $\alpha$ $(\mathrm{ER} \alpha)$ by combined green tea polyphenol and histone deacetylase inhibitor in ER $\alpha$-negative breast cancer cells. Mol Cancer. 2010; 9: 274. doi: 10.1186/1476-4598-9-274. PMID: 20946668, PMCID: PMC2967543.

57) Stendell - Hollis NR, Thomson CA, Thompson PA, Bea JW, Cussler EC, Hakim IA. Green tea improves metabolic biomarkers, not weight or body composition: a pilot study in overweight breast cancer survivors. J Hum Nutr Diet. 2010; 23(6): 590-600. doi: 10.1111/j.1365-277X.2010.01078.x. PMID: 20807303, PMCID: PMC2966548.

58) Landis-Piwowar K, Chen D, Chan TH, Dou QP. Inhibition of catechol-O-methyltransferase activity in human breast cancer cells enhances the biological effect of the green tea polyphenol (-)-EGCG. Oncol Rep. 2010; 24(2): 563-9. PMID: 20596647, PMCID: PMC3304301.

59) Huo C, Yang H, Cui QC, Dou QP, Chan TH. Proteasome inhibition in human breast cancer cells with high catechol-O-methyltransferase activity by green tea polyphenol EGCG analogs. Bioorg Med Chem. 2010; 18(3): 1252-8. doi: 10.1016/j.bmc.2009.12.034. PMID: 20045338, PMCID: PMC2819655.

60) Zhang Y, Han G, Fan B, Zhou Y, Zhou X, Wei L, et al. Green tea (-)-epigallocatechin-3-gallate downregulates VASP expression and inhibits breast cancer cell migration and invasion by attenuating Rac1 activity. European journal of pharmacology. 2009; 606(1-3): 172-9. doi: 10.1016/j.ejphar.2008.12.033. PMID: 19171136.

61) Shrubsole MJ, Lu W, Chen Z, Shu XO, Zheng Y, Dai Q, et al. Drinking green tea modestly reduces breast cancer risk. J Nutr. 2009; 139(2): 310-6. doi: 10.3945/jn.108.098699. PMID: 19074205, PMCID: PMC2646205.

62) Zhang M, Huang J, Xie X, Holman CD. Dietary intakes of mushrooms and green tea combine to reduce the risk of breast cancer in Chinese women. Int J Cancer. 2009; 124(6): 1404-8. doi: 10.1002/ijc.24047. PMID: 19048616.

63) Inoue M, Robien K, Wang R, Van Den Berg DJ, Koh WP, Yu MC. Green tea intake, MTHFR/TYMS genotype and breast cancer risk: the Singapore Chinese Health Study. Carcinogenesis. 2008; 29(10): 196772. doi: 10.1093/carcin/bgn177. PMID: 18669903, PMCID: PMC2574755.

64) Yiannakopoulou ECh. Effect of green tea catechins on breast carcinogenesis: a systematic review of invitro and in-vivo experimental studies. Eur J Cancer Prev. 2014; 23(2): 84-9. doi: 10.1097/CEJ.0b013e328364f23e. PMID: 23939462.

65) Wu Y, Zhang D, Kang S. Black tea, green tea and risk of breast cancer: an update. Springerplus. 2013; 2(1): 240. doi: 10.1186/2193-1801-2-240. PMID: 23750333, PMCID: PMC3671100.

66) Gu JW, Makey KL, Tucker KB, Chinchar E, Mao X, Pei I, et al. EGCG, a major green tea catechin suppresses breast tumor angiogenesis and growth via inhibiting the activation of HIF-1 $\alpha$ and $\mathrm{NFKB}$, and VEGF expression. Vasc Cell. 2013; 5(1): 9. doi: 10.1186/2045-824X-5-9. PMID: 23638734, PMCID: PMC3649947. 